This article was published in International Journal of Hydrogen Energy, 40(16), 56535663,2015

http://dx.doi.org/10.1016/j.ijhydene.2015.02.112

\title{
Composite-alumina-carbon molecular sieve membranes prepared from novolac resin and boehmite. Part I: Preparation, characterizationand gas permeation studies
}

\author{
Margot A. Llosa Tanco ${ }^{a, b}$, David A. Pacheco Tanaka ${ }^{a, b, *}$, \\ Sandra C. Rodrigues ${ }^{a}$, Miguel Texeira ${ }^{a}$, Adelio Mendes ${ }^{a * *}$ \\ a LEPABE-Faculdade de Engenharia, Universidade do Porto, Rua Dr. Roberto Frias, \\ 4200-465 Porto, Portugal

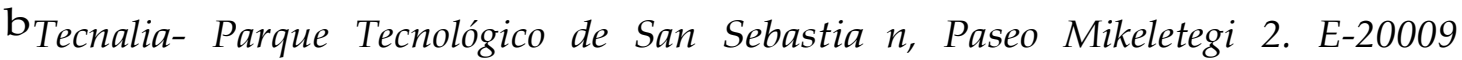 \\ Donostia, San Sebastian, Spain
}

\begin{abstract}
Supported composite alumina-carbon molecular sieve membranes (c-CMSM) were prepared from in house prepared novolac phenolic resin loaded with boehmite nanoparticles in a single dipping-drying-carbonization step. A porous a-alumina tube support was dipped into a N-methyl-2-pyrrolidone solution containing polymerized novolac resin loaded with boehmite, subsequently dried at $100{ }^{\circ} \mathrm{C}$ and carbonized at $500{ }^{\circ} \mathrm{C}$ under nitrogen environment. The structure, morphology and performance of the membranes were examined by scanning electron microscopy (SEM), X-ray diffraction (XRD), thermogravimetric analysis (TGA), carbon dioxide adsorption and permeation of $\mathrm{N} 2, \mathrm{O} 2, \mathrm{He}, \mathrm{H} 2$ and $\mathrm{CO} 2$. SEM showed carbon membranes with a thin and very uniform layer with a thickness of ca. $3 \mu \mathrm{m} \mathrm{CO} 2$ adsorption isotherms indicated that the produced carbon membranes presented a micro- porous structure. The c-CMSM exhibited good gas separation properties. The permselectivity surpass the Robeson upper bound for polymeric membranes, especially regarding ideal permselectivities of pairs $\mathrm{H} 2 / \mathrm{N} 2=117$, and $\mathrm{He} / \mathrm{O} 2=$ 49. Aging effects were observed after membrane exposure to ambient air. However with a thermal treatment under nitrogen atmosphere the permeance of nitrogen increases.
\end{abstract}

\section{Introduction}

Membrane processes for gas separation have improved remarkably over the 
past few decades. They are used commercially for hydrogen recovery, carbon dioxide removal from natural gas and on-site nitrogen production from air [1-3]. To achieve optimum performance for gas separation the membranes should exhibit both high permeability and selectivity. Many studies have been performed in order to improve the performance of membrane materials for gas separation and significant effort has been focused on the synthesis of gas separation membranes based on materials that provide better selectivity, thermal and chemical stability, than those already in use such as polymeric membranes [4]. Moreover, a highly selective membrane for gas separation has to allow separation between small molecules with similar sizes. Materials with these properties are molecular sieves made of silica, zeolites and carbon; compared to polymeric materials, these materials push the upper bound limits of the permeability $v s$ selectivity trade-off, reported in 1991 and 2008 by Robeson[5,6]. A relatively recent development in gas membrane separation is the preparation of carbon molecular sieve membranes (CMSM). They have been identified as very promising candidates for gas separation, both in terms of separation properties and selectivity. CMSM are produced by the carbonization of a polymeric precursor under an inert atmosphere or vacuum. CMSM have the greatest potential among the inorganic membranes of achieving excellent selectivity while sustaining the permeability and, unlike polymeric membranes, can function at high temperatures and in harsh environments [7e9]. CMSM have a unique microporous structure, which allows them to discriminate gas molecules by size and shape. The gas separation performance of carbon membranes depends on the critical pore size and pore size distribution. The openings contribute to the major part of the pore volume and are thus responsible for the adsorption capacity, while the constrictions are responsible for the selectivity [10]. The pores in carbon membranes are formed by packing imperfections be- tween ordered regions in the material and are described as slit-like with an idealized bimodal pore size distribution. The distribution consists of larger pores of 0.7-2 nm, known as micropores or galleries, connected by smaller pores of size $<0.7 \mathrm{~nm}$, known as ultramicropores. The larger sized micropores provide sorption sites, while the ultramicropores are the sieving sites; the combination of such two types of pores provides the combined molecular sieving function and high permeability characteristics of these materials [11,12].

The properties of CMSM are affected by many factors, such as carbonization temperature history, gas atmosphere and pre- or post-treatments. In addition, one of the most important factors to obtain high performance CMSM is the choice of the precursor. CMSM based on polyimide [11,13], phenolic resin [14e18], 
polyfurfuril alcohol [19] and cellulose [20,21], have been previously reported. Phenolic resins are desirable precursors to prepare CMSMs, since they present the advantage of being inexpensive and possess high carbon yield [14,15,22], withstanding elevated temperatures without losing their shape. They are very stable, with a high glass transition temperature, decomposing before achieving their melting point, assuring this way a resultant defect-free carbon structure. Phenolic resins are the product of the poly-condensation reaction of phenol with formaldehyde; their structure and properties depend on the formaldehyde/phenol ratio $(\mathrm{F} / \mathrm{P})$, catalyst, $\mathrm{pH}$ and temperature [23]. There are two forms of phenolic resins: resol and novolac. Resol resins are the product of basic catalysis in excess of formaldehyde $(\mathrm{F} / \mathrm{P}>1)$. Resol resins are not stable because the polymerization reaction continues with the time due to the presence of reactive methylol groups in the resin and their properties will depend on the basic catalysts used during their preparation. Novolac resins are obtained in acidic media and the amount of formaldehyde is lower, usually with an $\mathrm{F} / \mathrm{P}$ of ca. 0.75-0.85. Novolac resins have no reactive methylol groups in their molecules and therefore, without hardening groups, are incapable of condense with other molecules on heating; to complete the condensation reaction, it is necessary to add formaldehyde and/or amine to achieve the cross-linking.

In order to obtain high permeation rates, the selective layer of gas separation membranes should be as thin as possible. Due to mechanical requirements, thin membranes must be supported in macroporous layers [24]. Furthermore, obtaining membranes on an inorganic tube is useful for scaling-up applications. Hennis and Tripodi [25] stated that is rather difficult to achieve an adequate thin skin without pinholes when coating on a porous support; highlighting the advantages of using thicker coatings over highly porous substrates to avoid the fabrication problems that occur with thinner layers. Since surface roughness and the presence of large pores on the support inhibit the deposition of thin membrane films, several dipping-drying-carbonization cycles are required to obtain carbon membranes without defects. In order to decrease the number of cycles, asymmetric supports are used [26,27], Centeno and Fuertes [28] describe the preparation of carbon membranes with thickness of 2 and $3 \mu \mathrm{m}$ in a single step.

In this work, the incorporation of ceramic nanoparticles of boehmite in the novolac phenolic resin originated a defect- free and highly permeable c-CMSM in a single dipping- drying-carbonization step over a ceramic porous support. Former experiments using pure resin resulted in an irregular coating layer that penetrated into the porous support. The use of vacuum for the dipping allowed the solution to go inside the pores below the surface of the support leading to the 
production of thinner layers much less prone to cracks.

It was verified that the existence of oxygen-based functional groups on the surface of the carbon membranes could enhance the adsorption of water vapor increasing the water obstruction effect [29], which limits the applicability of this type of membranes. Although there are chemically and thermally resistant, CMSM present significant problems related to their performance stability; they appear to be more vulnerable to oxidation, humidity and to blockage of the pore [4]. Additional pore constrictions may be incorporated in the pore system by oxygen chemisorption and by strong adsorption of species presenting very low diffusivity; they block the pores and difficult the permeation of other species. Additionally, the presence of water can strongly reduce the permeability toward other species.

Our team reported previously [17] the preparation of composite aluminaCMSM using a resol resin as a polymer precursor. It was produced a 3-5 $\mu \mathrm{m}$ thick composite uniform layer on top of an $\alpha-\mathrm{Al}_{2} \mathrm{O} 3$ support. The composite top layer exhibited $\mathrm{Al} 2 \mathrm{O} 3,1-2 \mathrm{~nm}$ thick and 10-30 $\mathrm{nm}$ long well dispersed in a microporous carbon matrix. The c-CMSM exhibited ideal $\mathrm{O}_{2} / \mathrm{N}_{2}$ and $\mathrm{C}_{3} \mathrm{H}_{6} / \mathrm{C} 3 \mathrm{H} 8$ permselectivities of 5 and 15, respectively. The effect of Ag was also evaluated and it was observed that the load of $\mathrm{Ag}$ enhanced the carbon membrane performance especially for $\mathrm{C}_{3} \mathrm{H}_{6} / \mathrm{C}_{3} \mathrm{H} 8$ separation, where the $\mathrm{C} 3 \mathrm{H} 6 / \mathrm{C} 3 \mathrm{H} 8$ permselectivity increased from a maximum of 15 to $38[17,18]$; however, since resol resins contain reactive methylol groups it has been realized that the permeation characteristics depends on the batch of the resin used and in the time elapsed since the resin was fabricated. The preparation of CMSM on a-alumina supports by carbonization at $500{ }^{\circ} \mathrm{C}$ and $550{ }^{\circ} \mathrm{C}$ of a resorcinolformaldehyde resin loaded with boehmite has been studied [30], the authors conclude that the membrane carbonized at $550{ }^{\circ} \mathrm{C}$ has more ultramicropores and a narrower pore size distribution and that the permselectivity after activation surpasses the Robeson upper bound for O2/N2 > 11.5.

In this work, novolac resin was synthesized and used for the preparation of supported composite CMSM in one dipping carbonization step. The dipping solution was prepared by polymerization of the novolac resin with formaldehyde and ethylenediamine and addition of nanoparticles of boehmite. After carbonization at $500{ }^{\circ} \mathrm{C}$ under nitrogen atmosphere, a carbon matrix with homogeneously distributed $\mathrm{Al} 2 \mathrm{O} 3$ nano- fillers was obtained. The permeability as well as permselectivities tow ard several gas species $\left(\mathrm{He}, \mathrm{CO} 2, \mathrm{O} 2, \mathrm{~N} 2\right.$ and $\left.\mathrm{H}_{2}\right)$ were determined. The decrease in performance of the c- CMSM due to air exposure (aging) was also addressed. 


\section{Experimental}

\section{Materials}

Phenol 90\% and Formaldehyde 37\% were supplied by Euro- resins Industrias Quimicas S.A. Oxalic acid 99\% (Wako) and N- methyl-2-pyrrolidone (NMP, 99.8\% purity by Sigma-Aldrich), were used without further purification. Boehmite (10 wt. \% Y-alumina dispersion), particle size 8 e18 nm, was supplied by Kawaken Fine Chemicals Co. Ltd. The permanent gases were supplied by Air Liquid (99.999\% pure). Other chemicals were of reagent grade.

\section{Preparation of novolac resin}

Novolac resin was synthesized by the acid-catalyzed phenol-formaldehyde condensation [31]. Typically, $32.5 \mathrm{~g}$ of phenol $90 \%(0.345 \mathrm{~mol})$ and $0.5 \mathrm{~g}$ of oxalic acid were placed in a $250 \mathrm{ml}$ three-necked flask that was fitted with stirrer and a reflux condenser. The solution was heated at $80^{\circ} \mathrm{C}$, then $23 \mathrm{~g}$ of formaldehyde $37 \%(0.285 \mathrm{~mol})$ were added drop wise during a period of $30 \mathrm{~min}$ and the reaction was kept under reflux for $h$. The formed resin was washed several times with hot water. After that, the excess of water was removed by distillation. The solid was further dried at $50^{\circ} \mathrm{C}$ under vacuum for $24 \mathrm{~h}$.

\section{Determination of the molecular weight}

The determination of the molecular weight distribution of the novolac polymer was analyzed by Gel permeation chromatography (GPC), with an IR detector from Polymer Laboratories PL-GPC-50 plus, with a Resipore column, for a molecular weight range between 200 and $400.000 \mathrm{~g} / \mathrm{mol}$, being the stationary phase styrene divinyl-benzene ethylbenzene. Polystirene was used as standard.

\section{Preparation of the $\alpha$-alumina support}

Carbon membranes were prepared over asymmetric porous a- $\mathrm{Al} 2 \mathrm{O} 3$ supports (manufactured by Inopor) with $200 \mathrm{~nm}$ average pore size. The tubes have an o.d. of $10 \mathrm{~mm}$, an i.d. of $7 \mathrm{~mm}$, and $70 \mathrm{~mm}$ length. The ends of the $\alpha-\mathrm{Al} 2 \mathrm{O} 3$ supports were attached to non-porous $\mathrm{Al}_{2} \mathrm{O} 3$ tubes (Omega Engineering Limited) and the surface of both tube ends was coated with a glass sealant (Nippon Electric Glass GA-13N/325) at $1150{ }^{\circ} \mathrm{C}$. One end of the alumina tube was closed with a non- 
porous alumina tube and enamel glass, leaving an effective length for dipcoating of approximately $50 \mathrm{~mm}$.

\section{Preparation of the dipping solution}

Novolac polymer precursor was dissolved in NMP to prepare a $36 \mathrm{wt} \%$ resin solution and stirred thoroughly for $24 \mathrm{~h}$ to form a homogeneus solution. The coating solution containing $13 \mathrm{wt} \%$ of novolac resin, $2.4 \mathrm{wt} \%$ of formaldehyde, $0.6 \mathrm{wt} \%$ of ethylenediamine, $0.8 \mathrm{wt} \%$ of boehmite solution and a $83.2 \mathrm{wt} \%$ of $\mathrm{NMP}$ was prepared, and heated to $100^{\circ} \mathrm{C}$ for $2 \mathrm{~h}$, for the polymerization process.

\section{Preparation of the membrane}

For the preparation of supported c-CMSM three steps were involved: (a) dip coating of the porous support, (b) drying and (c) carbonization. The process is schematically showed in Fig. 1.

(a) For the dip coating, the dry $\alpha-\mathrm{Al}_{2} \mathrm{O} 3$ support tube was immersed, for $10 \mathrm{~s}$, into the dipping solution (Fig. 1) and then taken out slowly from the solution; the impregnation of the solution was assisted by applying vacuum from inside the tube. The remaining precursor solution was placed in a Teflon dish to make unsupported composite films (used later for morphological characterization and $\mathrm{CO} 2$ adsorption experiments).

(b) Both supported and unsupported membranes were dried in an oven at $100{ }^{\circ} \mathrm{C}$ overnight. In order to obtain a highly homogeneous membrane, the tubular supported membranes were allowed to dry under continuous rotation inside the oven.

(c) The membranes were carbonized at $500{ }^{\circ} \mathrm{C}$ in a tubular furnace, inside a quartz tube, using N2 at flowing rate of approximately 150-200 $\mathrm{ml} \mathrm{min}^{-1}$. The heating rate used for all the experiments was $1^{\circ} \mathrm{C} \mathrm{min}^{-1}$ and the soaking time $2 \mathrm{~h}$. The unsupported films were either crushed into small flakes or milled before morphological characterization.

\section{Morphological and structural characterization}

\section{Thermogravimetric analysis (TGA)}

Thermogravimetric analysis was carried out in a Netzsch TG 209 F1 Iris thermogravimetric balance (resolution $0.1 \mu \mathrm{g}$ ). The amount of sample used in each batch was about $5 \mathrm{mg}$. The analyzed samples were: the novolac resin, 10 
wt. \% boehmite dispersion in water and a polymerized resin $p$ boehmite film. The boehmite dispersion and the resin + boehmite film were previously dried overnight at $90^{\circ} \mathrm{C}$ to remove most of the solvent. Characteristic curves under $\mathrm{N}_{2}$ were determined from 20 to $900^{\circ} \mathrm{C}$ (with a heating rate of $10^{\circ} \mathrm{C} \mathrm{min}^{-1}$ ). The heating protocol was reported elsewhere [20,32], and can be summarized as follows: temperature rises from room temperature up to $110{ }^{\circ} \mathrm{C}$ to remove all humidity, followed by a rise up to $950^{\circ} \mathrm{C}$ under $\mathrm{N} 2$, and a final burning step at 950 ${ }^{\circ} \mathrm{C}$ under $\mathrm{O} 2$ atmosphere.

\section{Scanning electron microscopy analysis (SEM)}

Samples of c-CMSM were characterized using a JSM 5600 LV SEM. The supported c-CMSM were fractured and sputtered with platinum, to allow better conductivity for SEM.

\section{$X$-ray analysis}

The X-ray diffraction patterns were measured using a Bruker M21X instrument, radiation $\mathrm{CuKa}$, detector $\mathrm{X}^{\prime}$ Celerator, secondary monochromator.

\section{Pore size characterization}

The microporosity of the carbon membrane was assessed from the $\mathrm{CO}_{2}$ adsorption isotherm at $273 \mathrm{~K}$. The equilibrium values were obtained using a gravimetric method set up, in a Rubotherm ${ }^{\circledR}$ magnetic suspension balance $\left( \pm 10^{-5} \mathrm{mg}\right.$ precision) as described elsewhere [33].

\section{Permeation experiments}

A shell-and-tube apparatus [17] equipped with a pressure controller (Horiba Stec, model UR-7340) and an STEC SF-2 film flow meter was used to measure the permeation of gases through the supported carbon membranes. The temperature was kept constant by using an oven having three independent heating zones.

The selected gas was introduced into the membrane tube from outer shell through the mass flow controller and the gas permeated through the membrane was led to a soap-bubble flow meter to determine the flow rate. Gas permeation to $\mathrm{N}_{2}$. O2, He. $\mathrm{H}_{2}, \mathrm{CO}_{2}$ and permselectivity results were determined in the experiments conducted with single gases at different tem- peratures $\left(30-140{ }^{\circ} \mathrm{C}\right)$ and pressure difference $(100-400 \mathrm{kPa})$, while the permeate side was at atmospheric pressure. 


\section{Results and discussion}

\section{Synthesis of novolac resin and preparation of Al-CMSM}

Novolac resins are obtained in acidic media. As mentioned previously, these resins have no reactive methylol groups in their molecules and therefore without hardening groups they are incapable of condense with other molecules of novolac on heating. To complete the condensation reaction, formaldehyde and ethylenediamina were added to achieve the cross- linking. Novolac resins are mixtures of isomeric polynuclear phenols of various chain lengths with an average of five to six phenolic nuclei per molecule. Since these resins do not have active groups they are stable.

In this work novolac resin was synthesized in order to use more reliable polymer sources. Since the product of the re- action depends in the method of preparation, it was decided to modify the traditional method by adding the formaldehyde solution drop by drop for a period of $20 \mathrm{e} 30 \mathrm{~min}$. In this method, the concentration of phenol in the reaction is always much higher than formaldehyde, therefore, at the beginning of the reaction, the formation of mono-substituted phenol in ortho position is preferred.

The molecular weight of the novolac resin determined by the GPC method, was $303 \mathrm{~g} \mathrm{~mol}^{-1}$ which correspond to a oligomer with three phenolic groups, see Fig. 2. Since the molecular weight of novolac resin is small, it is not suitable for deposition on the alumina porous support. Therefore, the resin was polymerized with formaldehyde and ethylenediamine by heating at $100{ }^{\circ} \mathrm{C}$ after the addition of boehmite nanoparticles. After that, a suitable coating solution was obtained. The dipped membrane was kept at $100^{\circ} \mathrm{C}$ and a solid composite polymeric resin was formed. The supported membranes were carbonized at 500 ${ }^{\circ} \mathrm{C}$ under N2 atmosphere. Fig. 3 shows the alumina support before dip-coating, after dip- coating and after carbonization.

\section{Thermogravimetric analysis (TGA)}

TGA analysis was used to evaluate the thermal degradation of the polymeric precursor. Fig. 4a, and $\mathrm{b}$ shows thermogravimetric graphs and the mass derivative curves for the novolac resin, and dip-coating solution, respectively. They illustrate the weight loss caused by the carbonization between room temperature and $950{ }^{\circ} \mathrm{C}$ under nitrogen atmosphere. Fig. 4a shows the release of volatiles below $200{ }^{\circ} \mathrm{C}$ and the decomposition of the resin between 200 and $600{ }^{\circ} \mathrm{C}$. TGA graph for the dipping solution film (Fig $4 \mathrm{~b}$ ) shows the first small 
weight loss below $150{ }^{\circ} \mathrm{C}$ which corresponds to the evaporation of absorbed water from the precursor and the release of some volatiles compounds; the weight loss between 150 and $200^{\circ} \mathrm{C}$ correspond mainly to the solvent (NMP); the main weight loss segment occurs between 200 and $500^{\circ} \mathrm{C}$ which corresponds to the decomposition of the polymer whose structure is destroyed and an intermediate material is formed. Weight loss continued at a slower rate up to and beyond $950^{\circ} \mathrm{C}$; during this step the resin undergoes slow degradation.

\section{Scanning electron microscopy analysis (SEM)}

Fig. 5 provides an example of the micrograph taken of the cross-sectional view of a carbonized membrane up to $500^{\circ} \mathrm{C}$. It can be observed a distinct thin layer of the carbon membrane that was uniformly formed on top of the $\alpha$ $\mathrm{Al}_{2} \mathrm{O} 3$ support with about $3 \mu \mathrm{m}$ of thickness.

\section{$X$-ray analysis $(X R D)$}

The structure of the c-CMSM carbonized at $500{ }^{\circ} \mathrm{C}$ was analyzed by XRD and the diffraction pattern was plotted in Fig. 6. In this pattern, two wide peaks at around $2 \theta=23^{\circ}$ and $44^{\circ}$ were obtained. These values were similar to those found in graphite [34]; however, the broadening of the peaks was indicative of the degree of amorphousness typical of porous carbon materials [34,35]. This confirmed the destruction of the structure of novolac resin by the heat treatment leading to an amorphous structure and the peaks were assigned to amorphous carbon. The XRD pattern shows no Bragg lines suggesting that $\mathrm{Al}_{2} \mathrm{O} 3$ was too small and or too spread in the matrix to be detected.

\section{Pore size characterization}

In this paper the microporosity of the carbon molecular sieve membranes was characterized using adsorption equilibrium information obtained by the adsorption of $\mathrm{CO} 2$ at $0{ }^{\circ} \mathrm{C}$. The adsorption equilibrium isotherm of $\mathrm{CO} 2$ was acquired by the gravimetric method in a Rubotherm ${ }^{\circledR}$ suspension magnetic balance with a precision of $10^{-5} \mathrm{mg}$ [33]. Fig. 7 presents the adsorption equilibrium isotherm of $\mathrm{CO}_{2}$ at $0{ }^{\circ} \mathrm{C}$ for $\mathrm{c}-\mathrm{CMSM}$ crashed flakes. The molecules are adsorbed as type I isotherm; it can be observed that the studied carbon membrane reach a plateau for the maximum adsorption capacity for relative pressures around 2 implying a significant volume fraction of micropores. 
The mechanism of adsorption in micropores is known as micropore filling and has been well described by Dubinin and co-workers [36,37]. The DubininRadushkevisch (DR) equation was used to fit the experimental results:

$$
\frac{\mathrm{W}}{\mathrm{W}_{0}}=\exp \left[-\left(\frac{\mathrm{RT} \ln \left(\mathrm{P}_{0} / \mathrm{P}\right)}{\mathrm{E}_{0}}\right)^{2}\right]
$$

where $W$ refers to the micropore volume filled at pressure $P, W$ is the total micropore volume, $E$ the characteristic energy, $P_{0}$ the vapor pressure of the free liquid, $\mathrm{R}$ is the gas constant and $\mathrm{T}$ is the absolute temperature. DR equation gives a reasonable description of adsorption in micropores when the curve obtained from $\mathrm{CO}_{2}$ is linear. Another equation (eq, 2) was proposed, the DubininAstakhov (DA) equation [38]:

$$
\frac{\mathrm{W}}{\mathrm{W}_{0}}=\exp \left[-\left(\frac{\mathrm{RT} \ln \left(\mathrm{P}_{0} / \mathrm{P}\right)}{\mathrm{E}_{0}}\right)^{n}\right]
$$

where $n$ is an adjustable parameter.

The adsorption isotherms obtained for $\mathrm{CO} 2$ on c-CMSM are not very linear and, therefore, the micropore volume and the characteristic energy were determined by fitting the Dubinin-Astakhov equation to the experimental data. Fig. 7 presents the characteristic curve for c-CMSM.

The suitability and the applicability of the DA equation when $n=2.30$ is observed from Fig. 8 as a straight line was obtained. A good agreement of the DA equation fitting with the characteristic curve is observed. The slope of the plot is related to the characteristic energy of the micropore, EO=12.2 kJ $\mathrm{mol}^{-1}$ and the intercept is related to the micropore volume, $W_{0}=0.13 \mathrm{~cm}^{3} \mathrm{~g}^{-1}$

To obtain a more detailed knowledge of the porous structure of the c-CMSM, their pore size distribution (PSD) was determined using the structure-based method developed by Nguyen et al.,[36,37]. Mainly, the method uses the Langmuir isotherm for all pores of size $r$, while the heterogeneity of the system is described by the distribution of micropores with different size, given by $f(r)$; the adsorption affinity constant $b$ pore is calculated. This method takes into account the potential energy $(E)$ when a molecule is adsorbed on a flat surface and Epore, which is the potential energy when a molecule is adsorbed inside a pore. A slit like pore configuration is assumed here and considers the potential energy of interaction between the graphite type walls and the probe gas molecule. Additionally this model distinguishes between the gas confined in the pore and the adsorbed state and considers the overall contribution of every pore. 
Further details about this method are described elsewhere [36,39]. The pore size distribution for c-CMSM-550 was obtained and is presented in Fig. 9.

The PSD of the c-CMSM (Fig. 9) showed a higher amount of smaller micropores; being the larger micropores between the range of $0.6-0.75 \mathrm{~nm}$, the majority of the pore volume lied below $0.83 \mathrm{~nm}$, thus belonging to ultramicropore range. This results are consistent with the PSD found for C-CMSM derived from the resol resin [17] showing both small and larger micropores (0.35-0.45 $\mathrm{nm}$ and 0.5-0.8 $\mathrm{nm}$ ). These small and larger micropores are the responsible for the permeability and selectivity results of the carbon molecular sieve membranes.

\section{Permeation experiments}

The performance of a carbon membrane is characterized by the gas permeability as well as the corresponding selectivities. N2 and O2 permeation were determined at room temperature just after membranes carbonization (fresh membranes) in order to avoid the adsorption of water; the exposure to the air was very short (just a few seconds). The feed pressure difference was varied between 100 and $400 \mathrm{kPa}$ (relative pressure) while permeate was kept at atmospheric pressure. The permeation results for four c-CMSM (91, 92, 93 and 94), produced in the same conditions, are presented in Table 1. All c- CMSM showed high gas permeance, with some selectivity towards $\mathrm{O} 2$ against N2. The permeation performances for all the studied membranes are similar which confirms the reproducibility of the used preparation method. After the permeation test of the "fresh membranes", they were left in the air on the bench at room temperature and then $\mathrm{N}_{2}$ and $\mathrm{O} 2$ permeation experiments were performed; the results are listed in Table 1. For comparison purposes, N2 and O2 permeances of the fresh and aged CMSM 91 are showed in Fig. 10. For both gases, the permeance decreased considerably. How- ever, this effect was more marked for $\mathrm{N} 2$ than $\mathrm{O} 2$ (approximately 40 times for $\mathrm{N} 2$ and 10 times for $\mathrm{O} 2$ ). On the other hand, O2/N2 selectivities for c-CMSM after one day of aging are higher than the fresh membranes but not similar (selectivities are between 5.1 and 7.1).

The permeance of various gases at various pressure differences, at room temperature, was carried out with CMSM 93 after 1 day aging; the results are illustrated in Fig. 11 and listed in Table 2. It can be observed that $\mathrm{N} 2$ and $\mathrm{H} 2$ have the lowest and highest permeation respectively. The $\mathrm{H}_{2} / \mathrm{N} 2$ selectivity at room temperature is 117. Palladium membranes have high selectivity, but they are very fragile at room temperature and the hydrogen permeation is very low [40]. Therefore the c- CMSM could be an alternative for hydrogen separation at room temperature. 
Fig. 12 shows the permeances of $\mathrm{N} 2(3.64 \AA), \mathrm{O} 2(3.46 \AA)$, $\mathrm{CO} 2(3.30 \AA), \mathrm{H} 2(2.90$ $\AA)$ and $\mathrm{He}(2.60 \AA)$ against their kinetic diameter. There is not a straightforward relation between permeability and the kinetic diameter of the permeant species. From N2 to $\mathrm{H} 2$, the permeance increased as size of the gas decreased; this is an indication of the molecular sieve separation for carbon membranes. However, the opposite is observed between $\mathrm{H} 2$ and He; the smaller He had lower permeation that the bigger $\mathrm{H}_{2}$. This fact is consistent with the gas transport through carbon membranes that combines sieving effect at the smaller micropores (contrictions) with the adsorption and diffusion of the permeant gases on the larger pores. Therefore, for gases weakly adsorbed ( $\mathrm{He}, \mathrm{O} 2$ and N2) the molecular sieving is predominant.

The permeances obtained for c-CMSM are consistent with the behavior observed by Robeson for the performance of polymeric membranes [6]; an increase in selectivity occurs at the expense of a decrease in permeability and vice-versa. The obtained results were placed into the semi-empirical plot developed by Robeson [6]. Fig. 13 shows the revised upper bound limits for $\mathrm{O}_{2} / \mathrm{N}_{2}, \mathrm{He} / \mathrm{N}_{2}, \mathrm{CO}_{2} / \mathrm{N}_{2}$, and $\mathrm{H}_{2} / \mathrm{N}_{2}$. These plots are broadly recognized as the state-of-the art curves for gas separation. It can be observed that the result for $\mathrm{H} 2 / \mathrm{N}_{2}$ is over the Robeson upper bound.

Permeability results of the novolac resin and those obtained in our previous work for resol phenolic resin [17] are listed in Table 3. It can be observed that the values of perm- selectivity of the various gases respect to nitrogen are very similar; however the permeability is higher with CMSM prepared with novolac resin.

\section{Stability in air and regeneration}

During the carbonization process the polymer precursor de- composes, gases are released leaving pores and high reactive carbons. When fresh membranes are exposed to air, water reacts with reactive places of the membrane (water chemisorption). As consequence, carbon containing oxygen groups are formed in the pores; these oxygen groups are hydrophilic producing the physical adsorption of water. Both phenomena reduce the effective size of the micropores.

In order to study the aging of membrane 91 carbonized at $500{ }^{\circ} \mathrm{C}, \mathrm{O} 2$ and $\mathrm{N} 2$ permeances at various times after leaving the membrane in the ambient air were measured (Table 4). The fresh membrane has high gas permeances but low $\mathrm{O} 2 / \mathrm{N} 2$ selectivity; after one day in the air, the permeance of both gases decrease 
in more than $90 \%$, however the selectivity to- wards $\mathrm{O} 2$ increased from 1.6 until 6.7. After 6 days of exposure to ambient air, the permeance decreases even more; $\mathrm{N} 2$ permeance was non detected (less than $0.1 \mathrm{~mol} \mathrm{~m}^{-2} \mathrm{~s}^{-1} \mathrm{~Pa}^{-1} \mathrm{x}$ $10^{-9}$ ), the $\mathrm{O} 2 / \mathrm{N} 2$ selectivity is estimated to be more than 14 . After the permeation measurement, the membrane was heated at $50^{\circ} \mathrm{C}$ for $1 \mathrm{~h}$ and the $\mathrm{O} 2$ and N2 flux through the membranes at various temperatures were determined. After this mild activation, it was observed that the gas permeation increased.

Again membrane 91 was exposed to ambient air for 48 days. After that, the membrane permeability towards $\mathrm{N}_{2}$ and $\mathrm{O}_{2}$ was measured. It was observed that the permeability of $\mathrm{N} 2$ decreased greatly, giving a clear indication of pore clogging with water vapor [29]. Afterwards, in-situ regeneration at $100{ }^{\circ} \mathrm{C}$ for 1 $h$ in N2 atmosphere was performed; the membrane selectivity towards N2 and $\mathrm{O} 2$ was ca. $75 \%$ of the value obtained after one day of exposure to ambient air.

A water desorption test was carried out with the c-CMSM. The membrane was left in ambient air for some more days and the effect of the temperature in the $\mathrm{N} 2$ permeation at $400 \mathrm{kPa}$ pressure difference was studied; in this experiment, the temperature of the permeation was increased at $0.7^{\circ} \mathrm{Cmin}^{-1}$ and the N2 permeance recorded as shown in Fig. 14a. It can be observed that as the temperature increases, N2 permeance increases; it is an indication that water is being removed. Below $100{ }^{\circ} \mathrm{C}$ the superficial water and water molecules in the pores more loosely bonded are removed. Above $100{ }^{\circ} \mathrm{C}$, the rate of water removal increases; this is more marked at around $150{ }^{\circ} \mathrm{C}$; the $\mathrm{N}_{2}$ permeance increases and around $300^{\circ} \mathrm{C}$ it is almost constant (around $20 \mathrm{~mol} \mathrm{~m} \mathrm{~m}^{-}$ $\left.2 \mathrm{~S}^{-1} \mathrm{~Pa}^{-1} \times 10^{-9}\right)$; all the water has been removed. The permeance of the fresh membrane was $78 \mathrm{~mol} \mathrm{~m}^{-2} \mathrm{~s}^{-1} \mathrm{~Pa}^{-1} \times 10^{-9}$ which is three times higher than the permeance of the membrane regenerated at $300{ }^{\circ} \mathrm{C}$. It seems that water reacted with the carbon active sites of the fresh membrane forming oxygen functional groups; these groups could not be removed at $300^{\circ} \mathrm{C}$, they remain in the membrane reducing the size of the pore.

Just after the regeneration experiment, without removing the membrane from the permeation system, the effect of the adsorbed water on $\mathrm{N}_{2}$ permeance at room temperature was studied. A boat containing water was introduced in the permeation system and the $\mathrm{N}_{2}$ permeance at $400 \mathrm{kPa}$ in function of the time was recorded (Fig 14b). At the beginning of the experiment, a sharp decrease of permeation is observed; water is being adsorbed in the most accessible places of 
the membrane. The adsorption is fast until $20 \mathrm{~min}$, after that, a gradual small decrease in permeation is observed; the water is being adsorbed in the inner pores of the membrane.

\section{Conclusions}

A thin composite carbon molecular sieve membrane (ca. $3 \mathrm{~mm}$ thickness) derived from phenolic resin novolac loaded with boehmite nanoparticles (8e18 $\mathrm{nm}$ ) was successfully prepared in a single dip-drying-carbonization step. Adsorption of $\mathrm{CO} 2$ at $0{ }^{\circ} \mathrm{C}$ was used to assess the ultramicroporosity of c-CMSM and the pore size distribution was determined to be between 0.3 and $0.8 \mathrm{~nm}$.

Permeance of the c-CMSM determined immediately after carbonization show high values, however the selectivity for $\mathrm{O} 2 / \mathrm{N} 2$ was low. In air, the active sites present in the fresh membranes react with water producing hydrophilic groups able to adsorb physically water, clogging some pores of the carbon membranes. After 1 day on ambient air, the permeance decreased, but increased the $\mathrm{O}_{2} / \mathrm{N}_{2}$ selectivity. The permeance properties of the c-CMSM were examined using pure $\mathrm{He}, \mathrm{H} 2, \mathrm{~N} 2, \mathrm{CO} 2$, and $\mathrm{O} 2$. The membranes showed good permeance results for all tested gases. The permeance versus kinetic diameter towards $\mathrm{He}, \mathrm{H}_{2}, \mathrm{~N}_{2}$, $\mathrm{CO} 2$ and $\mathrm{O} 2$ exhibited a molecular sieve mechanism for all the membranes prepared; this was in agreement with the micropore size in the $0.3 \mathrm{e} 0.8 \mathrm{~nm}$ range.

Aging effects were observed and after regeneration by heat treatment at $100{ }^{\circ} \mathrm{C}$ under nitrogen, ca. $75 \%$ of the initial performance was obtained. The performance of the $\mathrm{c}-\mathrm{CMSM}$ carbonized at $500{ }^{\circ} \mathrm{C}$ was above the Robeson upper bound for $\mathrm{H}_{2} / \mathrm{N}_{2}$ thus making it promising for the separation of hydrogen at low temperatures.

\section{Acknowledgments}

Margot Llosa Tanco and Miguel Texeira are grateful to the Portuguese Foundation for Science and Technology (FCT) for their doctoral grants (references SFRH/BD/61898/2009 and SFRH/BD/24768/2005). The authors are thankful to CEMUP for the SEM analysis (REEQ/1062/CTM/2005 and REDE/1512/RME/ 2005 funding provided by FCT). Thanks to Dr. J. Ochoa and S. Gil from the Energy and Environment Division (Tecnalia) for the molecular weight analysis. 


\section{References}

1. Bernardo P, Drioli E, Golemme G. Membrane gas separation: a review/state of the art. Ind Eng Chem Res May 2009;48(10):4638-63.

2. Baker RW. Future directions of membrane gas separation technology. Ind Eng Chem Res Mar. 2002;41(6):1393-411.

3. Baker RW, Lokhandwala K. Natural gas processing with membranes: an overview. Ind Eng Chem Res Apr. 2008;47(7):2109-21.

4. Saufi S. Fabrication of carbon membranes for gas separationeea review. Carbon N. Y 2004;42(2):241e59.

5. Robeson LM. Correlation of separation factor versus permeability for polymeric membranes. J Memb Sci Oct. 1991;62(2):165-85.

6. Robeson LM. The upper bound revisited. J Memb Sci Jul. 2008;320(1e2):390400 .

7. Ismail A, David L. A review on the latest development of carbon membranes for gas separation. J Memb Sci Oct. 2001;193(1):1-18.

8. Jones CW, Koros WJ. Carbon molecular-sieve Gas separation membranes

.2. Regeneration following organic-exposure. Carbon N Y 1994;32(8):1427-32.

9. Shiflett MB, Foley HC. Ultrasonic deposition of high-selectiviy nanoporous carbon membranes. Science Sep. 1999;285(5435):1902-5.

10. Koresh JE, Soffer A. The carbon molecular sieve membranes. General properties and the permeability of $\mathrm{CH} 4 / \mathrm{H} 2$ mixture. Sep Sci Technol Feb. 1987;22(2-3):973-82.

11. Steel KM, Koros WJ. Investigation porosity carbon Mater Relat Eff gas Sep Prop, 41; 2003. p. 253-66.

12. Singh R, Koros WJ. Carbon molecular sieve membrane performance tuning by dual temperature secondary oxygen doping (DTSOD). J Memb Sci Jan. 2013;427:472-8.

13. Wang K, Suda H, Haraya K. The characterization of $\mathrm{CO} 2$ permeation in a CMSM derived from polyimide 2003;31:61-9.

14. Fuertes A, Menendez I. Separation of hydrocarbon gas mixtures using phenolic resin-based carbon membranes. Sep Purif Technol Jul. 2002;28(1):29-41. 15. Centeno T, Vilas J, Fuertes A. Effects of phenolic resin pyrolysis conditions on carbon membrane performance for gas separation. J Memb Sci Jan. 2004;228(1):45-54.

16. Katsaros FK, Steriotis TA, Stubos AK, Mitropoulos A, Kanellopoulos NK, Tennison $S$. High pressure gas permeability of microporous carbon membranes. Microporous Mater 1997;8(3,4):171-6.

17. Teixeira M, Campo MC, Pacheco Tanaka DA, Llosa Tanco MA, Magen C, 
Mendes A. Composite phenolic resin-based carbon molecular sieve membranes for gas separation. Carbon N Y Nov. 2011;49(13):4348-58.

18. Teixeira M, Campo M, Pacheco Tanaka DA, Llosa Tanco MA, Magen C, Mendes A. Carbon-A12O3-Ag composite molecular sieve membranes for gas separation. Chem Eng Res Des Dec. 2012;90(12):2338-45.

19. Shiflett MB, Foley HC. Reproducible production of nanoporous carbon membranes. Carbon N Y Aug. 2001;39(9):1421-5.

20. Campo MC, Magalhães FD, Mendes A. Carbon molecular sieve membranes from cellophane paper. J Memb Sci Mar. 2010;350(1-2):180-8.

21. Gilron J, Soffer A. Knudsen diffusion in microporous carbon membranes with molecular sieving character. J Memb Sci Nov. 2002;209(2):339-52.

22. Centeno T, Fuertes A. Supported carbon molecular sieve membranes based on a phenolic resin. J Memb Sci Jul. 1999;160(2):201-11.

23. Pizzi A, Mittal KL. Handbook of adhesive technology, revised and expanded. CRC Press; 2003. p. 1024.

24. Baumann S, Meulenberg WA, Buchkremer HP. Manufacturing strategies for asymmetric ceramic membranes for efficient separation of oxygen from air. J Eur Ceram Soc Jul. 2013;33(7):1251-61.

25. Hennis 1981 Composite hollow fiber membranes for gas separation the resistance model approach.".

26. Ichikawa and T. Tomita, Ceramic filter, US20080105613 A108-may-2008.

27. Ichikawa, H. Nonaka, and T. Tomita, Separation membrane complex, and method for production of separation membrane complex, WO 2009001970 A131-Dec- 2008.

28. T. Centeno and A. Fuertes, Method for preparing carbon membranes for separating gases, WO 006288526-Apr-2001.

29. Lagorsse S, Magalhã es FD, Mendes A. Aging study of carbon molecular sieve membranes. J Memb Sci Mar. 2008;310(1-2):494-502.

30. Rodrigues SC, Whitley R, Mendes A. Preparation and characterization of carbon molecular sieve membranes based on resorcinol-formaldehyde resin. J Memb Sci Jun. 2014;459:207-16.

31. Braun. Polymer synthesis theory and practice fundamentals methods experiments. 4th ed. Springer; 2012.

32. Ottaway M. Use of thermogravimetry for proximate analysis of coals and cokes. Fuel Aug- 1982;61(8):713-6.

33. Campo MC, Magalhães FD, Mendes A. Comparative study between a CMS membrane and a CMS adsorbent: part IdMorphology, adsorption equilibrium and kinetics. J Memb Sci Jan. 2010;346(1):15-25.

34. Hussain R, Qadeer R, Ahmad M, Saleem M. X-Ray diffraction study of heat- 
treated graphitized and ungraphitized carbon. Turk J Chem 2000;24:177-83.

35. Lua AC, Su J. Effects of carbonisation on pore evolution and gas permeation properties of carbon membranes from Kapton ${ }^{\circ}$ polyimide. Carbon N Y Nov. 2006;44(14):2964-72.

36. Nguyen C, Do DD. Adsorption of supercritical gases in porous Media: determination of micropore size distribution. J Phys Chem B Aug. 1999;103(33):6900e8.

37. Nguyen C, Do DD, Haraya K, Wang K. The structural characterization of carbon molecular sieve membrane (CMSM) via gas adsorption. J Memb Sci Aug. 2003;220(1-2):177-82.

38. Gil A, Korili SA, Cherkashinin GY. Extension of the DubinineAstakhov equation for evaluating the micropore size distribution of a modified carbon molecular sieve. J Colloid Interface Sci Jul. 2003;262(2):603-7.

39. Rutherford SW, Do DD. Characterization of carbon molecular sieve 3A. Langmuir Sep. 2000;16(18):7245-54.

40. Pacheco Tanaka DA, Llosa Tanco MA, Nagase T, Okazaki J, Wakui Y, Mizukami F, et al. Fabrication of hydrogen- permeable composite membranes packed with palladium nanoparticles. Adv Mater Mar. 2006;18(5):630-2.

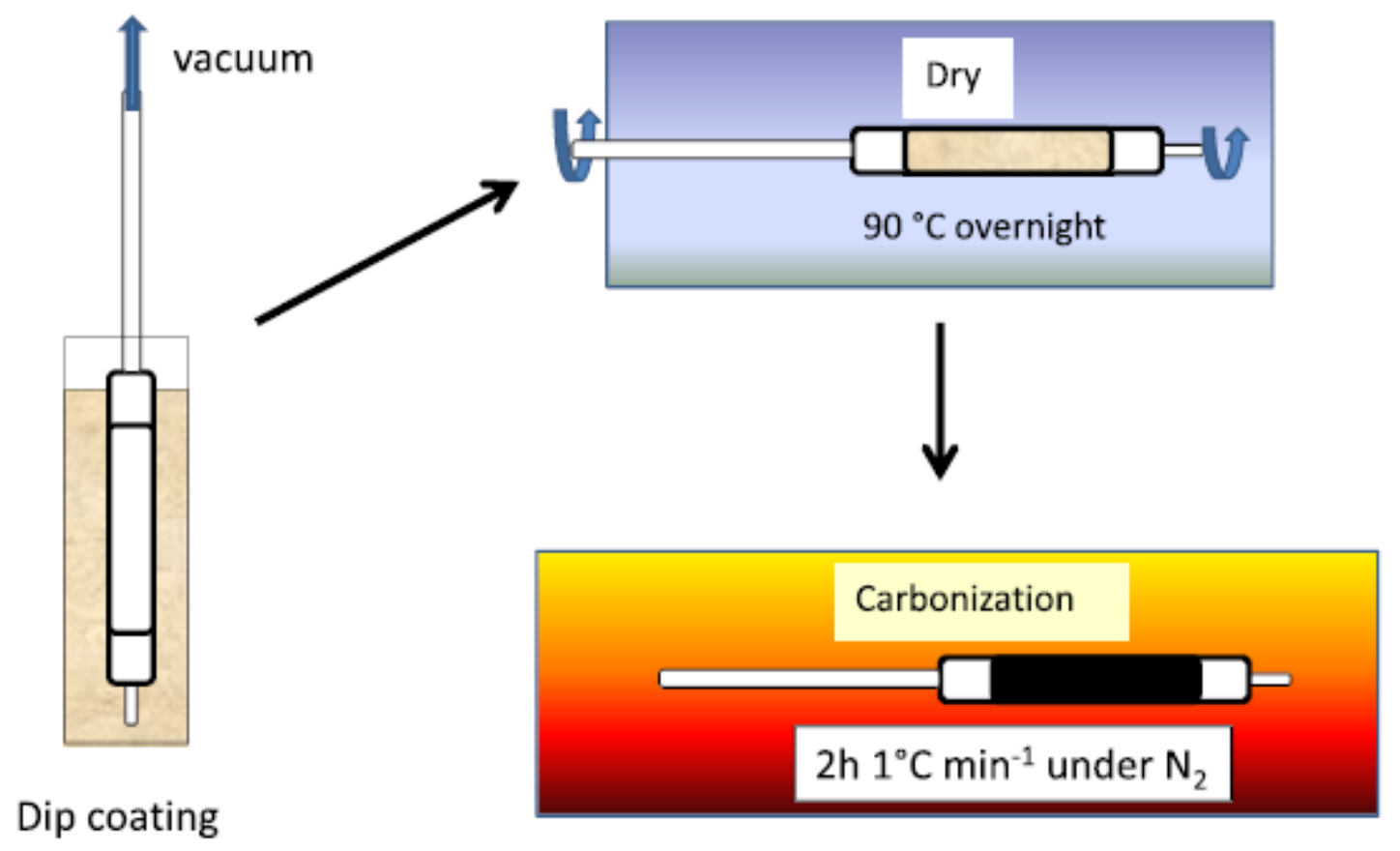

Fig. 1 - Fabrication of c-CMSM. 
<smiles>Oc1ccccc1Cc1cccc(Cc2ccccc2O)c1O</smiles>

Fig. 2 - Structure of the synthesized novolac

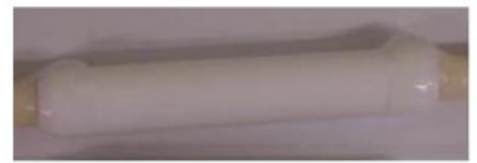

$\alpha$-Alumina

support

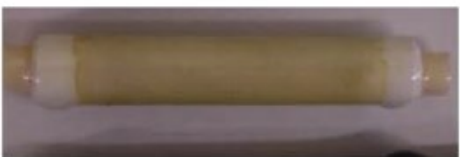

Support after coating

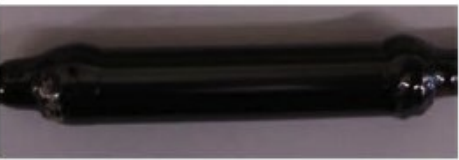

C-CMSM

Fig. 3 - Porous alumina support, support after dip coated and dried and cCMSM after carbonization.

a)

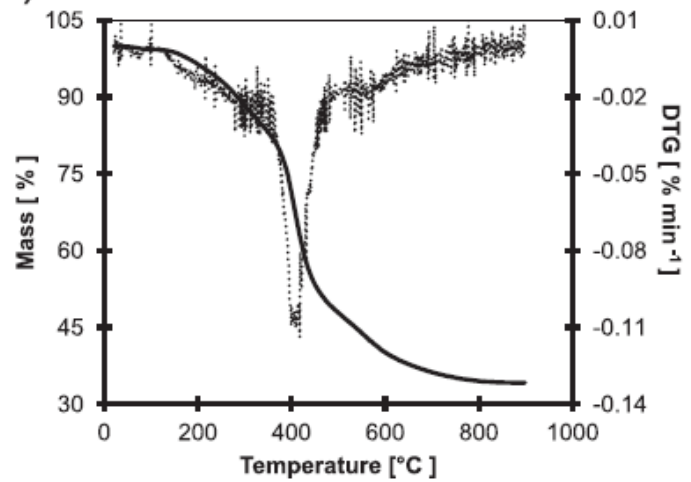

b)

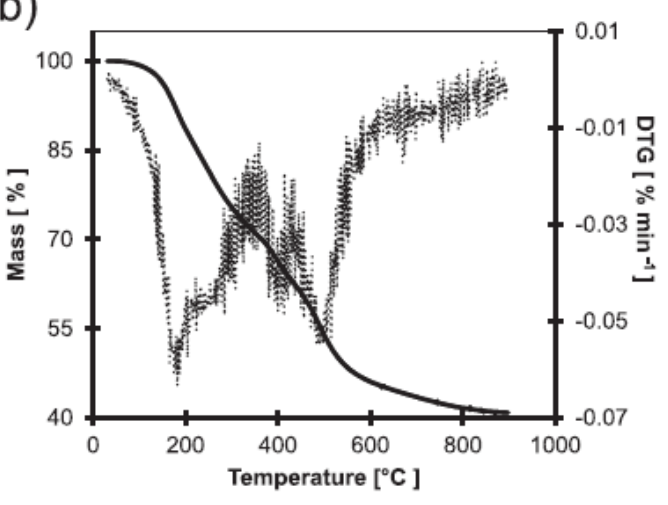

Fig. 4 - TGA graphs and correspondent derivative curve for the a) novolac resin, b) dip-coating solution after heat treatment at $100{ }^{\circ} \mathrm{C}$ for $24 \mathrm{~h}$. 


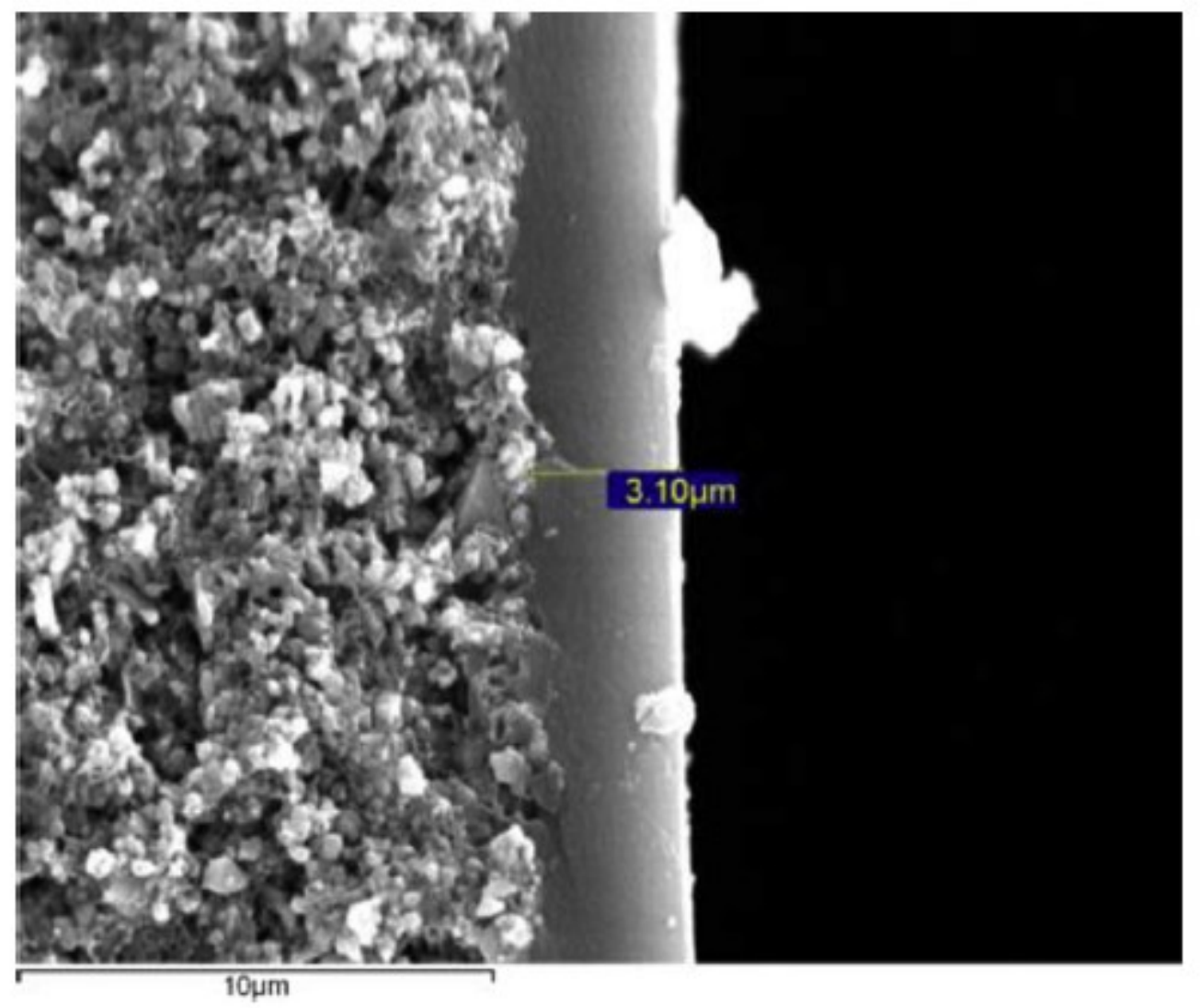

Fig. 5 - SEM micrograph of the cross-section region of the alumina support and the c-CMSM.

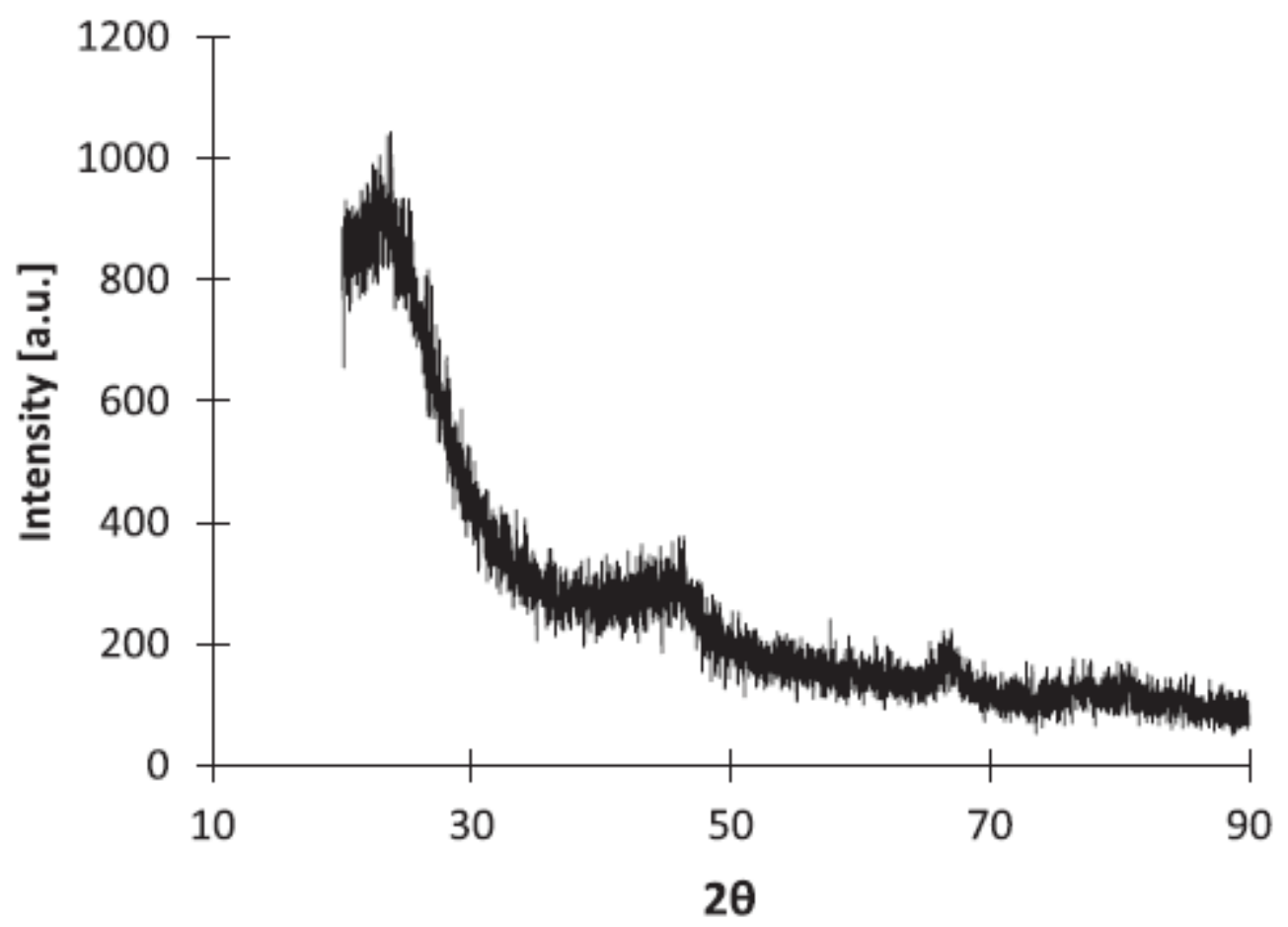

Fig. 6- X-ray diffraction spectrum of the c-CMSM carbonized at $500{ }^{\circ} \mathrm{C}$. 


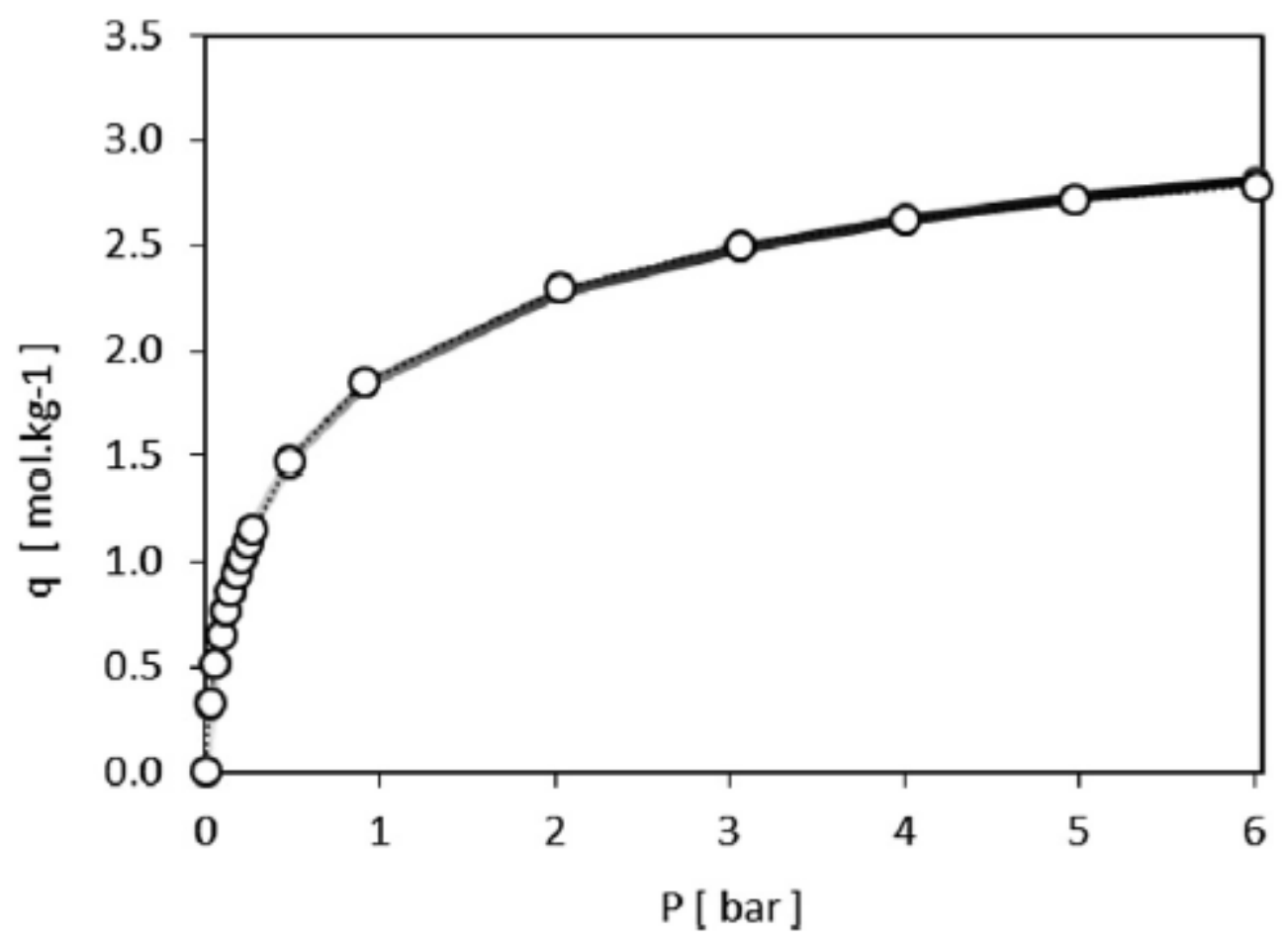

Fig. 7 - Adsorption equilibrium isotherm for $\mathrm{CO} 2$ at $0{ }^{\circ} \mathrm{C}$ for the $\mathrm{c}-\mathrm{CMSM}$ carbonized at $550{ }^{\circ} \mathrm{C}$.

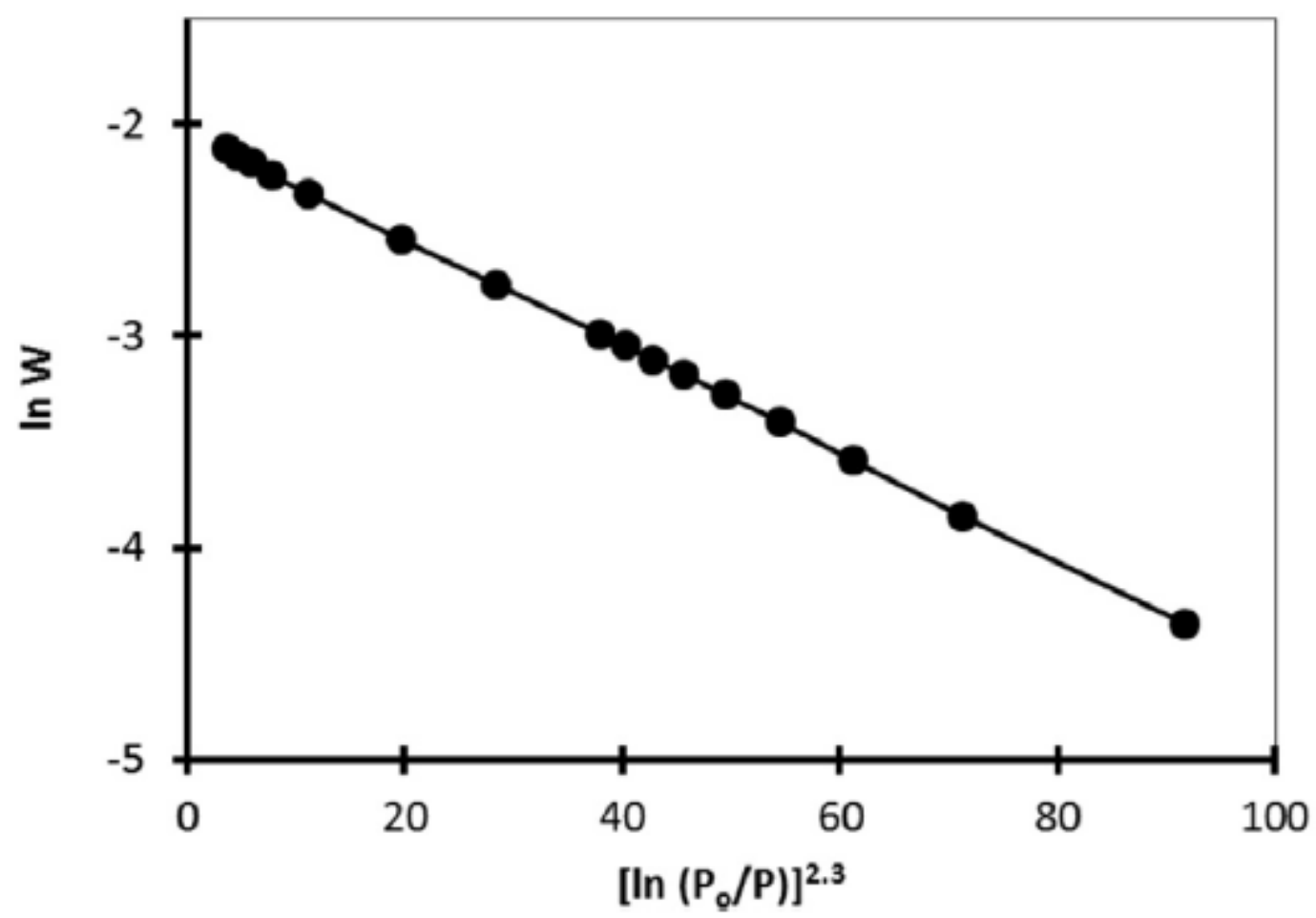

Fig. 8 - Carbon dioxide characteristic curve for the c- CMSM-550. 


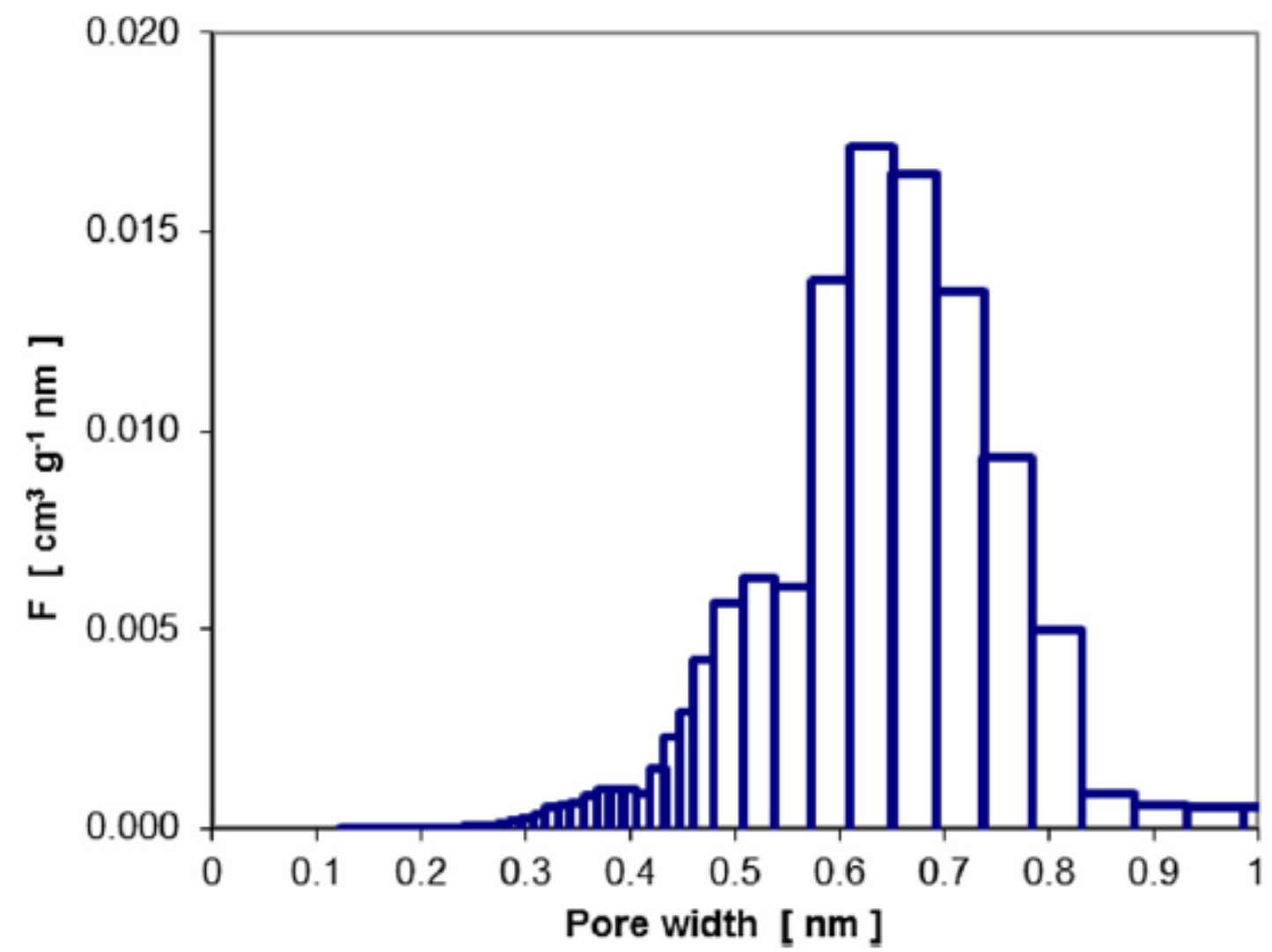

Fig. 9 - Micropore size distribution of c-CMSM carbonized at $550{ }^{\circ} \mathrm{C}$.
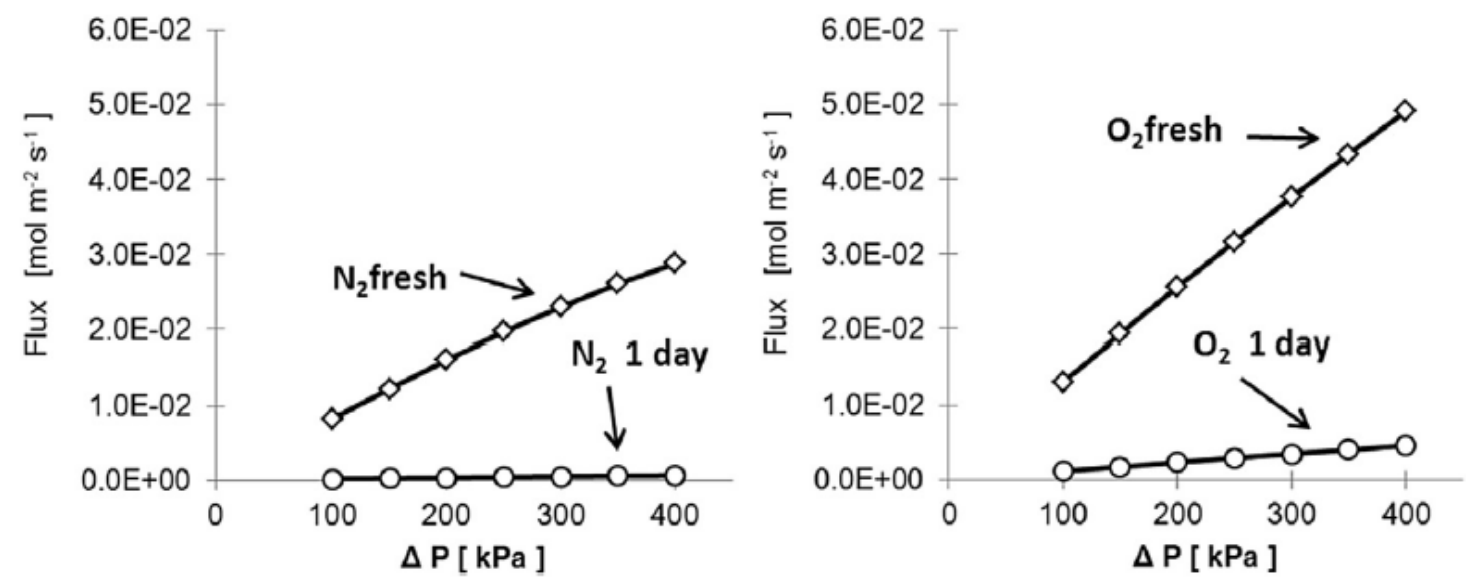

Fig. 10 - Flux as a function of the relative feed pressure for $\mathrm{O} 2$ and N2 at room temperature $\left(20-25^{\circ} \mathrm{C}\right)$ for $\mathrm{c}-\mathrm{CMSM}-91$ fresh and after 1 day aging. 


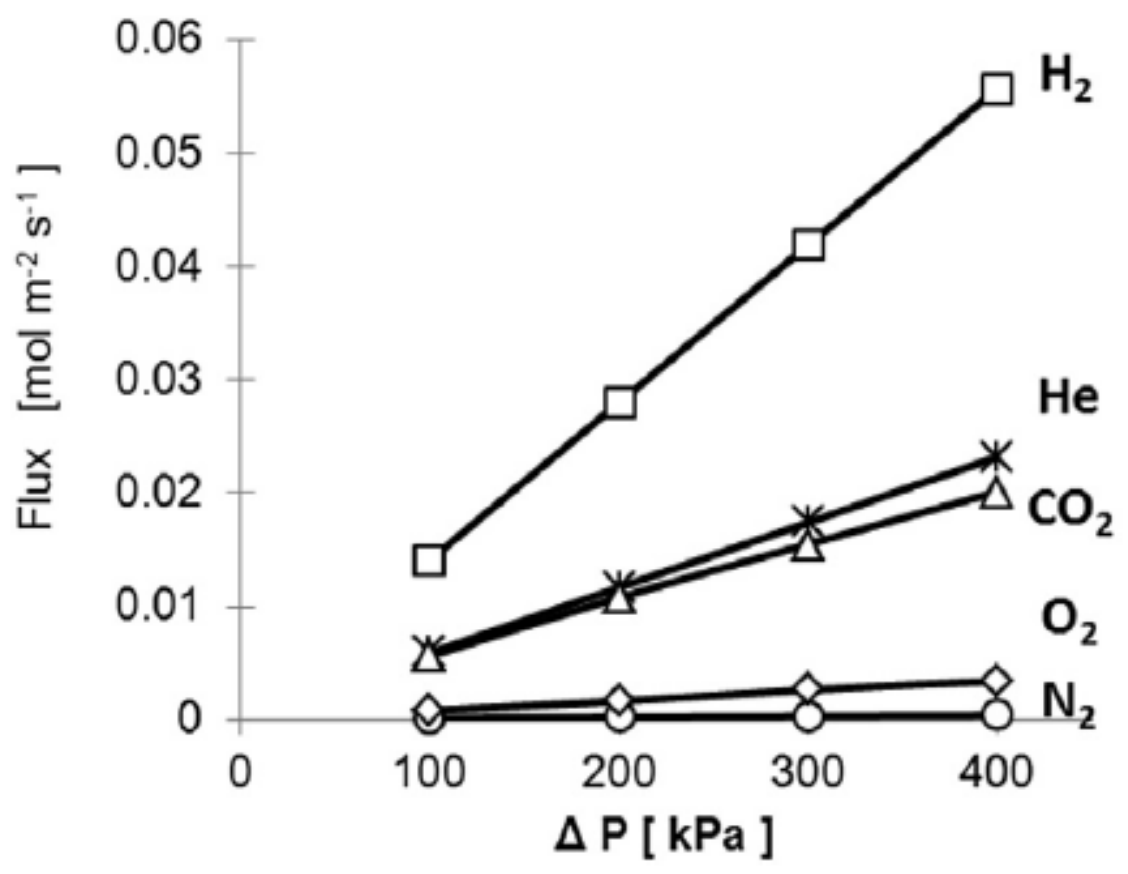

Fig. $11-\mathrm{H} 2, \mathrm{He}, \mathrm{CO} 2, \mathrm{O} 2$ and $\mathrm{N} 2$ flux at room temperature $\left(20-25{ }^{\circ} \mathrm{C}\right)$ for membrane 93.

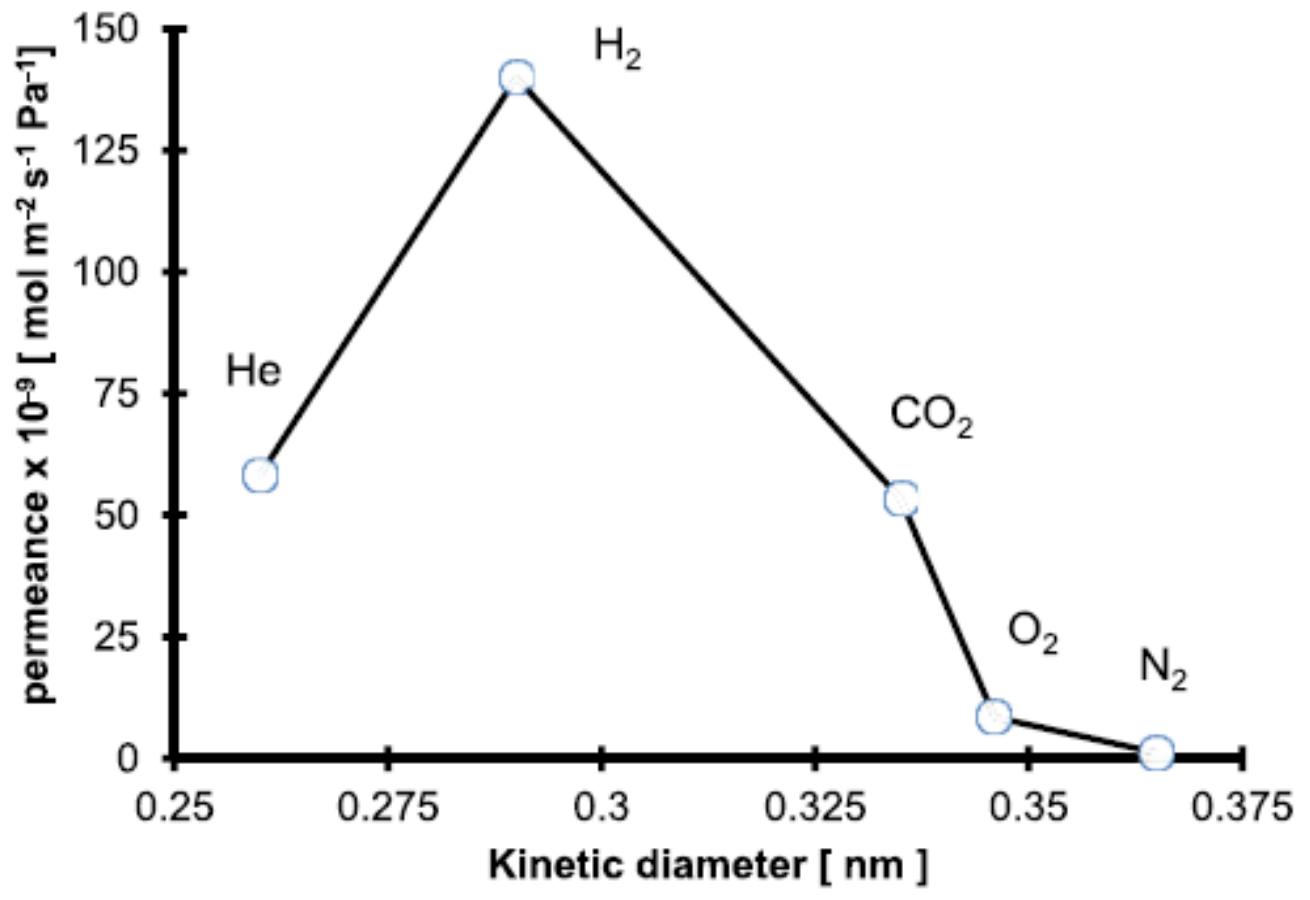

Fig. 12 - Permeance as a function of the gas kinetic diameter for c-CMSM 93. 

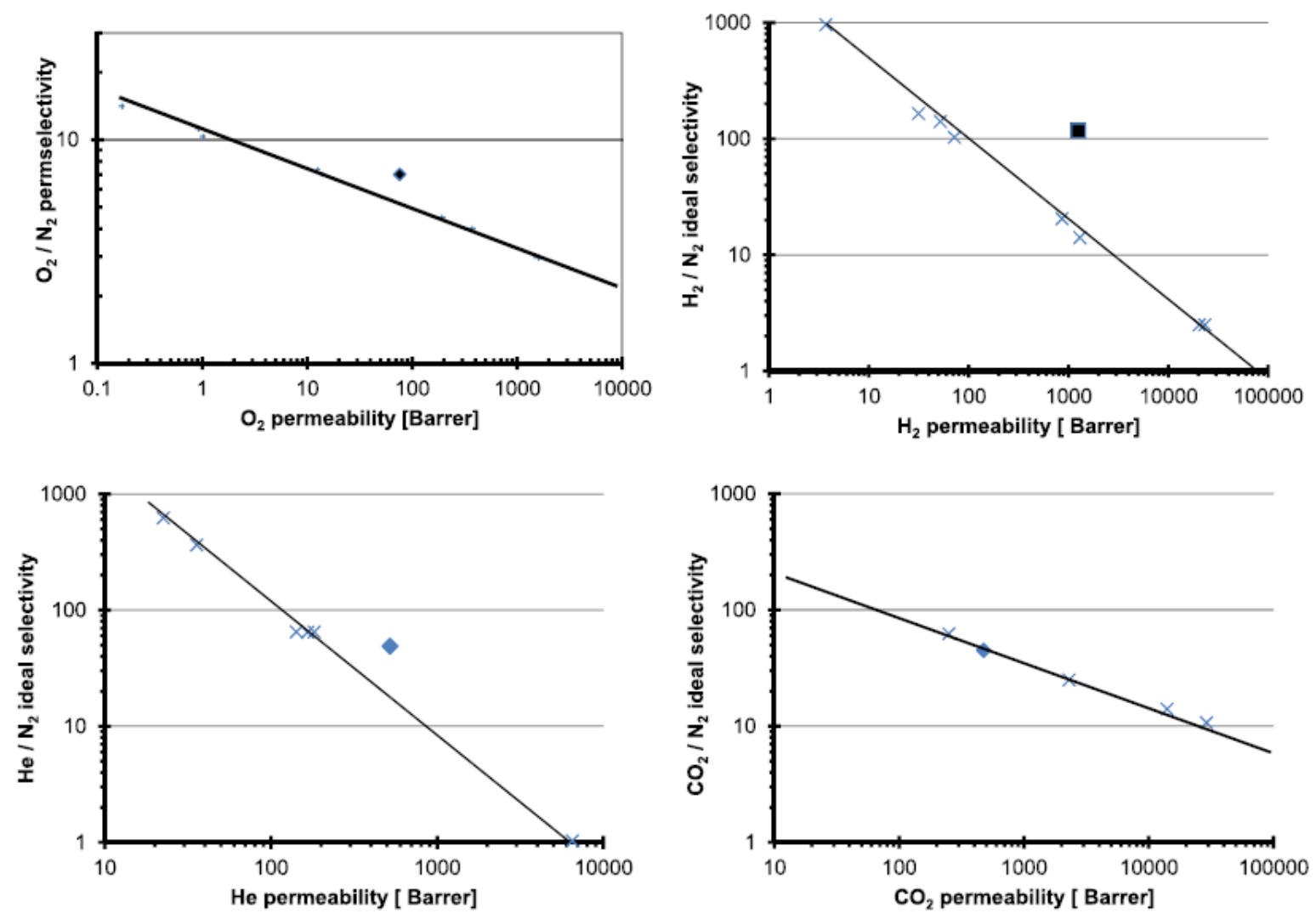

Fig. 13 - Gas permeation results for four gas pairs of interest in c-CMSM 500 and comparison with the respective upper bound plots.

(a)

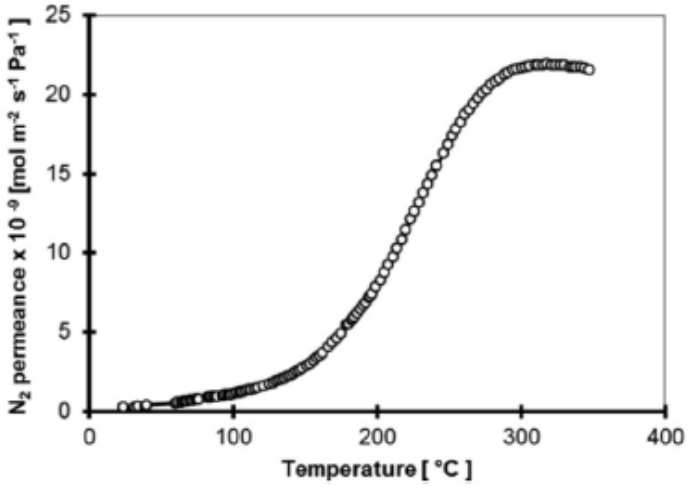

(b)

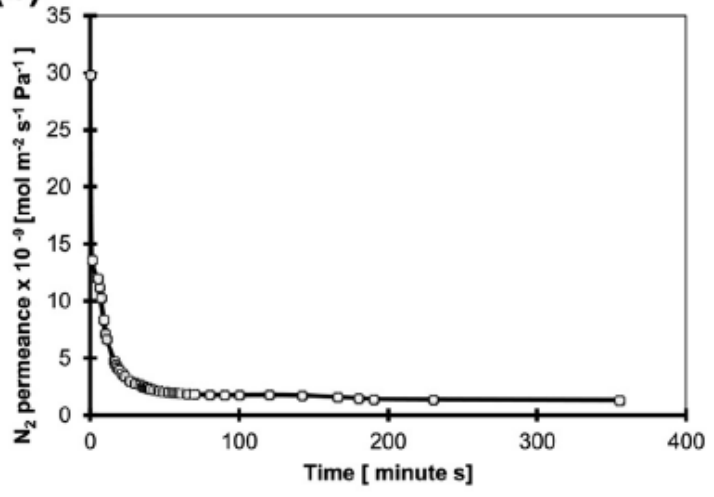

Fig. 14 - N2 permeance at $400 \mathrm{kPa}$ pressure difference: (a) in function of temperature (heating rate $0.7{ }^{\circ} \mathrm{C} \mathrm{min}^{-1}$ ), (b) in function of time of water adsorption (after regeneration at $300^{\circ} \mathrm{C}$ ). 


\begin{tabular}{|c|c|c|c|c|c|c|}
\hline & \multicolumn{3}{|c|}{ Fresh c-CMSM } & \multicolumn{3}{|c|}{1 day aged c-CMSM } \\
\hline & \multicolumn{2}{|c|}{$\begin{array}{l}\text { Permeance } \\
\mathrm{mol} \mathrm{m}^{-2} \mathrm{~s}^{-1} \\
\mathrm{~Pa}^{-1} \times 10^{-9}\end{array}$} & \multirow[b]{2}{*}{$\mathrm{O}_{2} / \mathrm{N}_{2}$} & \multicolumn{2}{|c|}{$\begin{array}{l}\text { Permeance } \\
\mathrm{mol} \mathrm{m}^{-2} \mathrm{~s}^{-1} \\
\mathrm{~Pa}^{-1} \times 10^{-9}\end{array}$} & \multirow[b]{2}{*}{$\mathrm{O}_{2} / \mathrm{N}_{2}$} \\
\hline & $\mathrm{N}_{2}$ & $\mathrm{O}_{2}$ & & $\mathrm{~N}_{2}$ & $\mathrm{O}_{2}$ & \\
\hline 91 & 78 & 130 & 1.6 & 1.8 & 12 & 6.7 \\
\hline 92 & 74 & 110 & 1.5 & 2.4 & 12 & 5.1 \\
\hline 93 & 80 & 140 & 1.7 & 1.2 & 8.5 & 7.1 \\
\hline 94 & 68 & 120 & 1.8 & 1.1 & 7.3 & 7.0 \\
\hline
\end{tabular}

\begin{tabular}{|c|c|c|}
\hline Gas & $\begin{array}{c}\text { Permeance } \\
\mathrm{mol} \mathrm{m}{ }^{-2} \mathrm{~s}^{-1} \mathrm{~Pa}^{-1} \times 10^{-9}\end{array}$ & Selectivity $\mathrm{X} / \mathrm{N}_{2}$ \\
\hline $\mathrm{N}_{2}$ & 1.2 & \\
\hline $\mathrm{O}_{2}$ & 8.5 & 7 \\
\hline $\mathrm{CO}_{2}$ & 53.4 & 45 \\
\hline $\mathrm{He}$ & 58.2 & 49 \\
\hline $\mathrm{H}_{2}$ & 140 & 117 \\
\hline
\end{tabular}

Table 3 - Comparison for the permeances and permselectivies of the c-CMSM derived from resol and from novolac (this work).

\begin{tabular}{|c|c|c|c|c|}
\hline \multirow{2}{*}{ - } & Resol resin [18] & & Novolac (this work) & \\
\hline & Permeance mol m${ }^{-2} \mathrm{~s}^{-1} \mathrm{~Pa}^{-1} \times 10^{-9}$ & $\mathrm{x} / \mathrm{N}_{2}$ & Permeance mol m${ }^{-2} \mathrm{~s}^{-1} \mathrm{~Pa}^{-1} \times 10^{-9}$ & $\mathrm{x} / \mathrm{N}_{2}$ \\
\hline $\mathrm{N}_{2}$ & 0.7 & & 1.2 & \\
\hline $\mathrm{O}_{2}$ & 4.6 & 6.5 & 8.5 & 7 \\
\hline $\mathrm{CO}_{2}$ & 30.6 & 43 & 53 & 44 \\
\hline $\mathrm{He}$ & 37.8 & 53 & 58 & 48 \\
\hline $\mathrm{H}_{2}$ & & & 140 & 117 \\
\hline
\end{tabular}




\begin{tabular}{|c|c|c|c|}
\hline \multirow[t]{2}{*}{ Days } & \multicolumn{2}{|c|}{ Permeance $\mathrm{mol} \mathrm{m}{ }^{-2} \mathrm{~s}^{-1} \mathrm{~Pa}^{-1} \times 10^{-9}$} & \multirow[b]{2}{*}{$\mathrm{O}_{2} / \mathrm{N}_{2}$} \\
\hline & $\mathrm{N}_{2}$ & $\mathrm{O}_{2}$ & \\
\hline 0 & 78 & 130 & 1.6 \\
\hline 1 day & 1.8 & 12 & 6.7 \\
\hline 6 days & n.d. $<0.1$ & 0.7 & \\
\hline \multicolumn{4}{|c|}{ Activation at $50^{\circ} \mathrm{C} / 1 \mathrm{~h}$} \\
\hline $50{ }^{\circ} \mathrm{C}$ & 0.4 & 2.2 & 6.3 \\
\hline $75^{\circ} \mathrm{C}$ & 0.5 & 3.4 & 6.3 \\
\hline $100^{\circ} \mathrm{C}$ & 2.2 & 12 & 5.3 \\
\hline $140^{\circ} \mathrm{C}$ & 5.9 & 22 & 3.7 \\
\hline 48 days & n.d. ${ }^{\circ} 0.05$ & 1.4 & \\
\hline \multicolumn{4}{|c|}{ Activation at $100^{\circ} \mathrm{C} / 1 \mathrm{~h}$} \\
\hline $25^{\circ} \mathrm{C}$ & 0.3 & 1.5 & 5.4 \\
\hline $50{ }^{\circ} \mathrm{C}$ & 0.5 & 1.9 & 4.0 \\
\hline $75^{\circ} \mathrm{C}$ & 0.7 & 3.2 & 5.0 \\
\hline
\end{tabular}

